\title{
Original Articles
}

\section{Presence of Diabetic Complications in Type 1 Diabetic Patients Correlates with Low Expression of Mononuclear Cell AGE-Receptor-1 and Elevated Serum AGE}

\author{
Ci-jiang He, ${ }^{1}$ Theodore Koschinsky, ${ }^{2}$ Christina Buenting, ${ }^{2}$ and Helen Vlassara ${ }^{1}$ \\ ${ }^{1}$ Division of Experimental Diabetes and Aging, Mount Sinai School of Medicine, New York, \\ New York, USA \\ ${ }^{2}$ Diabetes Research Institute, Dusseldorf, Germany \\ Accepted November 20, 2000
}

\begin{abstract}
Background: Receptors for advanced glycation endproducts (AGE-R) mediate AGE turnover, but can also trigger inflammatory genes that promote diabetic tissue injury and diabetic complications (DC). High AGE levels and reduced AGE-R sites in kidneys of NOD mice prone to type 1 diabetes (TID) and to renal disease (RD) suggested that impaired AGE-R function may contribute to RD in these mice.

Materials and Methods: In this study, after confirming reduced AGE-RI expression in NOD mouse peritoneal macrophages, we tested for differences in AGE-R1, -R2, and -R3 gene expression in 54 human subjects by RT-PCR and Western analysis. Fresh peripheral blood mononuclear cells (PBMN) were isolated from 36 persons: 18 T1D patients with severe RD (DC); 11 age-and DM-duration matched patients without DC (n-DC); and 7 normal volunteers (NL). EBV-transformed lymphoblasts were obtained from an additional 18 subjects (12 TID patients, 6 with and 6 without DC, and 6 nondiabetics).

Results: AGE-RI mRNA and protein of PBMN from $\mathrm{n}$-DC patients were enhanced ( $p<.05$ versus NL) in pro-
\end{abstract}

\section{Introduction}

It is well recognized that severe diabetic complications (DC) develop only in a subset $(\sim 30 \%)$ of diabetic patients, seemingly independent of glycemic control or duration of disease $(1,2)$. This has fueled a search for genes that directly or indirectly influence key diabetic complications, such as vasculopathy and nephropathy. Although several candidates

Address correspondence and reprint requests to: Helen Vlassara, MD, Mount Sinai Medical School, Box 1640, One Gustave L. Levy Place, New York, NY 10029. Telephone: 212-659-155 l Fax: 212-849-2652; E-mail: helen.vlassara@mssm.edu portion to serum AGE levels (sAGE) $(p<.005$ versus NL). In contrast, PBMN from DC patients exhibited no up-regulation of AGE-RI mRNA or protein, despite higher sAGE levels $(p<.005$ versus NL). A similar unresponsiveness in AGE-Rl gene expression was observed in EBV-transformed lymphoblasts from DC patients versus NL $(p<.01)$, but not in n-DC $(p=\mathbf{N S})$. AGE-R2 and -R3 mRNA and protein levels were enhanced in both TID groups (DC $>$ n-DC) (n-DC AGER3, $p<.05$, DC AGE-R3, $p<.05)$ compared to NL. AGER2 mRNA levels correlated with sAGE levels $(r=.61$, $p<.05)$, and with creatinine clearance $(r=-.63, p<$ .05). No differences were noted in AGE-R2 and -R3 mRNA expression in cultured cells.

Conclusions: The consistent pattern of elevated serum AGE and low expression of AGE-R l gene in macrophages from TID mice (NOD), fresh PBMN and EBV-transformed cells from TID patients with advanced DC suggests ineffective regulation of Rl-mediated AGE turnover, possibly of genetic basis. have been identified (3-5), it is now acknowledged that such genes need not be linked to diabetes, but may be induced by diabetes $(6,7)$.

Glucose-derived glycoxidation products known as advanced glycation endproducts (AGEs) are produced at elevated levels in diabetics. There is mounting molecular and biochemical evidence that AGEs, together with their cellular receptors (AGE-R), may be important determinants of tissue homeostasis, as well as long-term diabetic complications (8-10). Among the known AGE receptors, AGE-R-1, a 48-kDa protein, with typical short extracellular domain, a single transmembrane segment, and 
cytoplasmic domain (11) corresponds to the first molecule, p60, identified as being involved in AGE uptake $(11,12)$. AGE-R2, an 80-87 kDa AGEinducible tyrosine-phosphorylated protein kinase $\mathrm{C}$ substrate (11, 13-15), co-purified with AGE-R1 but with no direct AGE-binding activity. However, its rapid phosphorylation by $A G E$ has suggested that it may be involved in AGE-signaling (15). AGE-R3, or galectin-3 (15-18), lacks secretory and transmembrane domains but contains a high-affinity AGEbinding region at the C-terminus (16). Other receptors interacting with AGEs include RAGE, which engages AGE and non-AGE ligands and has been linked to increased reactive oxygen species (ROS) $(19,20)$ and ScR-II, which also has multiple ligands, and has been implicated in several disorders $(21,22)$. Murine and human AGE-receptor genomic organization, chromosomal locations $(17,20,23)$, and several gene polymorphisms (24; F. Cambien, INSERM, Paris, France, personal communication) have been identified in most of these molecules, none of which exhibits a clear connection to DC. In regard to function, the expression and binding activity of AGE receptors have been shown to be elevated in monocyte/macrophages, vascular, and other cells from animal models and humans with insulin-dependent diabetes (TID) $(18,25-27)$, including cultured monocytes exposed to model AGEs (28). Although AGE-induced cell activation has been linked to several receptors (29), this could also involve glycoxidant-generated cellular stress, independent of AGE-receptor pathways (30,31).

A limited number of studies have addressed the regulation of receptor-dependent AGE turnover, reporting an enhancement in TID (25) and a decline in activity in aging rodents (32). Furthermore, reactive catabolic derivatives of native tissue- or diet-derived AGEs are only partially excreted in the urine (33). A decline in renal function retards further AGE clearance, inducing significant AGE retention in blood and tissues $(33,34)$, and further accelerating renal/ vascular injury in diabetic patients.

Among the known models of spontaneous TID, non-obese diabetic (NOD) mice exhibit a significant genetic susceptibility to glomerulopathy independent of hyperglycemia $(35,36)$. These mice exhibit a reduction in the gene expression of, and AGE binding by, AGE-R1 in renal mesangial cells, combined with early tissue AGE accumulation $(37,38)$. NOD mice also exhibit a reciprocal up-regulation of kidney AGE-R3, and to a lesser extent, RAGE and ScR-II (37). In the context of the early overexpression of growth factors, for example, TGF $\beta-1$ and matrix components e.g., $\alpha$ IIV collagen and tenascin found in this model [36], these findings suggest that a primary impairment of AGE removal within the kidney in this strain of mice may set the stage for AGE accumulation and cell activation, promoting renal injury.

Because these studies were concerned only with the properties of kidney-specific (mesangial cell)
AGE receptors in the NOD mouse, no conclusions could be drawn about the state of AGE-R on macrophages, the principal cell-based AGE removal system. Therefore, as reported below, we tested NOD mouse macrophages for their ability to bind and degrade AGEs, and found both functions abnormally reduced.

We subsequently assessed peripheral blood mononuclear cells (PBMN) from well-matched TID patients with or without severe DC for a possible association between AGE-R expression, circulating AGEs, and susceptibility to DC, with a focus on AGE$\mathrm{R} 1$ and the associated components-R2 and-R3 (39). In addition, we examined AGE-R expression in human EBV-transformed lymphoblasts from matched nondiabetic controls and TID subjects to define whether the receptor phenotype expressed in vivo is preserved in cultured transformed lymphoblasts, which would suggest a genetic mechanism (39). The possible role of AGE-R dysfunction in promoting the development of DC in TID is discussed.

\section{Materials and Methods \\ Animal Studies}

Three 4-month-old newly diabetic (D-NOD), nondiabetic (ND-NOD), and age-matched ILI (diabetesresistant, genetically related to NOD) $(n=10$ per group) were obtained from Jackson Labs (Bar Harbor, ME, USA). Peritoneal macrophages were isolated by peritoneal lavage under mild ether anesthesia, as described $(12,26)$. To assay for serum AGE, mice were sacrificed by $\mathrm{CO}_{2}$, and blood was collected; the mice were then perfused extensively through the aorta with sterile phosphate-buffered saline (PBS) containing RNAse inhibitor (Boehringer Mannheim, Indianapolis, IN, USA). The kidneys were rapidly removed for immediate processing or frozen at $-80^{\circ} \mathrm{C}$. Sections of kidney cortex were homogenized and digested, as described in (27) for AGE measurement. Peritoneal macrophage preparations $\left(1 \times 10^{6}\right.$ cells/well) from each group of mice were cultured in complete medium (DMEM, with 10\% fetal bovine serum [FBS], Gibco, Gaithersburg, MD, USA), plus penicillin $(100 \mathrm{U} / \mathrm{ml})$ and streptomycin $(100 \mathrm{U} / \mathrm{ml})$ for ligand binding and degradation studies as per standard methods $(11,12,16,25,28)$.

Human Studies: Patients, PBMN, and EBV-Lymphoblast Cultures

Cells from a total of $\mathbf{5 4}$ individuals were studied; fresh PBMN were obtained from 36 patients and studied at the Diabetes Research Institute (DRI), Dusseldorf, Germany after signing an approved informed consent. The remaining 18 subjects were studied at the Joslin Diabetes Clinic and served as the source for production of EBV-transformed lymphoblasts (kindly provided by Dr. A. Krolewski) and as described below (40). The clinical characteristics of the former group of 36 patients are presented in Table 1. Height, weight, 
Table 1. Clinical characteristics and serum and renal AGE parameters of donors of fresh PBMN

\begin{tabular}{|c|c|c|c|}
\hline Group & NL & $\mathrm{Dm} / \mathrm{nDC}$ & Dm/DC \\
\hline Subjects $(n)$ & 7 & 11 & 18 \\
\hline $\operatorname{Sex}(M / F)$ & $6 / 1$ & $4 / 7$ & $10 / 8$ \\
\hline Age (years) & $43 \pm 11$ & $37 \pm 10$ & $47 \pm 13$ \\
\hline HbAlc $(\%)$ & $5.3 \pm 0.4$ & $7.8 \pm 1.6^{*}$ & $8.6 \pm 0.8^{*}$ \\
\hline Serum AGEs (U/mL) & $2.5 \pm 1.6$ & $6.0 \pm 3.4^{*}$ & $8.0 \pm 3.6^{*} \S$ \\
\hline Urine AGEs $\left(\mathrm{U} \times 10^{3} / \mathrm{mL}\right)$ & $175 \pm 70$ & $256 \pm 66^{*}$ & $153 \pm 55$ \\
\hline Total cholesterol (mg/dL) & $208 \pm 46$ & $194 \pm 29$ & $226 \pm 44$ \\
\hline Triglycerides (mg/dL) & $106 \pm 51$ & $83 \pm 54$ & $140 \pm 55^{\S}$ \\
\hline Creatinine (mg/dL) & $0.81 \pm 0.15$ & $0.80 \pm 0.12$ & $0.98 \pm 0.26$ \\
\hline UAER (ug/min) & $4.1 \pm 1.1$ & $4.1 \pm 1.1$ & $851 \pm 75^{* *}$ \\
\hline $\operatorname{Ccr}(\mathrm{mL} / \mathrm{min})$ & $105 \pm 33$ & $106 \pm 17$ & $87 \pm 30$ \\
\hline $\mathrm{C}_{\mathrm{AGE}}\left(\mathrm{U} \times 10^{3} / \mathrm{min}\right)$ & $3.0 \pm 0.18$ & $4.42^{*} \pm 0.26$ & $2.16^{* *} \pm 0.12$ \\
\hline
\end{tabular}

Data are expressed as mean \pm SD.

${ }^{*} p<.005$ vs NL.

${ }^{* *} p<.001$ vs NL and $\mathrm{D} / \mathrm{nDC}$.

$\mathrm{s}_{p}<.05$ vs $\mathrm{DM} / \mathrm{nDC}$.

UAER, urinary albumin excretion rate; $C_{c r}$, creatinine clearance; $C_{A G E}$ AGE clearance.

and blood pressure (after 15 min of rest) were recorded for all subjects; additionally, nephropathy was determined by three separate $3 \mathrm{hr}$ timed collections of urine, and urine albumin excretion rate (UAER, expressed as $\mu \mathrm{g} / \mathrm{min}$ ) measured by ELISA $(40,41)$. Serum HbAlc, total plasma cholesterol, triglycerides, and serum and $24 \mathrm{hr}$ urinary creatinine were determined by standard methods $(33,34)$. The presence of retinopathy was determined by fundus examination and photography, and graded as minimal, background, or proliferative according to the modified Airie House classification (42). Among the 36 subjects from DRI, 11 were diagnosed with TID (mean duration: $20.2 \pm 3.6$ years), but with no DC (n-DC); namely, no nephropathy (UAER $<20 \mu \mathrm{g} / \mathrm{min}$ ), normal blood pressure (BP), and no or minimal retinopathy. Eighteen patients with T1D (mean duration: $27.0 \pm$ 8.3 years) showed signs of overt nephropathy (UAER $>300 \mu \mathrm{g} / \mathrm{ml}$ ), background or proliferative retinopathy, and high BP or vascular disease (DC). All T1D patients were on a regimen of multiple injections of insulin. The remaining 7 patients were normal volunteers (aged 27-46 years). Selection criteria included normal fasting blood glucose, absence of hypertension, cardiovascular disease, renal disease, or smoking.

Mononuclear cell fractions from these subjects were separated from $40 \mathrm{ml}$ whole blood, using a standard density gradient centrifugation (Ficoll-Paque) method, as described elsewhere $(12,28)$. Cells were resuspended in RPMI medium with $10 \%$ fetal bovine serum. Immediately after isolation, $1 \times 10^{7}$ cells per patient were used for mRNA or protein extraction.
In addition, EBV-transfected lymphoblast cell lines from 18 subjects were obtained (Dr. A. Krolewski, Joslin Diabetes Center, Boston, MA, USA). The diabetic patient donors were selected from among a large group previously described (40). That study included 162 Caucasian patients who developed T1D before age 21 , and were followed at the Joslin Clinic for 2 years after diagnosis of diabetes. The mean age was $34 \pm 2$ years and duration of diabetes was $18 \pm 0.5$ years. Nephropathy was also determined by a $3 \mathrm{hr}$ collection of urine (40) and albumin excretion, measured by radioimmunoassay (RIA; Diagnostic Products Corp, Los Angeles, CA, USA). Proteinuria was defined as overt if UAER $>300 \mu \mathrm{g} / \mathrm{min}$; those subjects with UAER $<20$ $\mu \mathrm{g} / \mathrm{min}$ were considered to have neither albuminuria nor nephropathy. The UAER of those with renal disease (DM/DC) was $2612 \pm 670 \mathrm{ug} / \mathrm{min}$, and of those without (DM/n-DC), $7.5 \pm 1.0 \mu \mathrm{g} / \mathrm{min}$. Immortalized lymphoblast cell lines for two randomly selected groups of patients included six T1D patients with end-stage renal disease (DM/DC), and six age-matched TID patients without renal disease (DM/n-DC). Cells from a group of six healthy nondiabetic persons (NL) were also included as controls (40). Lymphoblasts $\left(1 \times 10^{7}\right.$ per patient $)$ were suspended in RPMI (10\% FBS) and subjected to RNA isolation, as described previously (36).

Antibodies, Ligands, and Assays

Previously characterized IgG, isolated from rabbit antisera raised against recombinant human AGE-R 1 
(rhAGE-R1) and AGE-R2 (rhAGE-R2), were affinity purified as described (12). The two resulting IgG fractions have been previously found to exhibit R I or R2 immunoreactivity against human, mouse, or rat tissue extracts $(12,18,26)$. Rat monoclonal anti-human AGE-R3 was purified from culture supernatants of hybridoma M3/38 (ATCC TIB 166), using a protein G-sepharose column (Boehringer Mannheim Biochemicals, Indianapolis, IN, USA) (16) and was used together with an isotypic rat IgG (Sigma Chemical Co, St. Louis, MO, USA).

Low-endotoxin bovine serum albumin (BSA) (Sigma), passed over an affi-Gel Blue column (Bio-Rad, Hercules, CA, USA), a heparin-Sepharose CL6B column (Pharmacia, Upsala, Sweden), and an endotoxin-binding affinity column (Pierce, Rockford, IL, USA) to remove various contaminants, was incubated with or without $0.5 \mathrm{M}$ D-glucose in $0.2 \mathrm{M}$ phosphate buffer ( $\mathrm{pH} \mathrm{7.4)}$ at $37^{\circ} \mathrm{C}$ for 4 weeks under sterile conditions $(12,16,37)$. Low-molecular-weight reactants and free glucose were removed by dialysis against PBS. An AGE-ELISA $(43,44)$ was used to determine the levels of AGE-modified BSA ( $325 \mathrm{U} / \mathrm{mg}$ protein) and unmodified BSA (0.8 U/mg protein).

Aliquots of each preparation were radioiodinated by the Iodo-Bead method (Pierce) $(12,16)$. After TCA $(20 \%)$ precipitation, $>95 \%$ of ${ }^{125} \mathrm{I}$ was protein bound (specific activity: $\sim 1.0-1.5 \times 10^{3} / \mathrm{ng}$ protein).

\section{Ligand Blot, Western Blot Analyses, and RT-PCR}

To isolate total cellular protein, cell suspensions were centrifuged briefly and the pellets were resuspended in lysis buffer containing Triton-X $100(0.5 \%)$ and protease inhibitors for $1 \mathrm{hr}$ at $4^{\circ} \mathrm{C}$. Nonsolubilized cell fragments were separated after centrifugation at 15,000 times for $1 \mathrm{hr}$, and protein concentration was determined by BCA Protein Assay (Pierce). Cell membrane fractions were isolated by standard ultracentrifugation methods, as described (12).

Ligand blotting was carried out on whole cell extracts or cell membranes, as described previously $(12,26)$. Briefly, $10-20 \mu \mathrm{g}$ protein fractions suspended in Laemli sample buffer containing $2 \%$ $\beta$-mercaptoethanol were electrophoresed ( $12 \%$ SDSPAGE). Proteins were transferred onto nitrocellulose (NC) membranes $(0.2 \mathrm{~mm}$ pore size) (Bio-Rad). The NC membranes were blocked with $2 \%$ BSA in PBS for $1 \mathrm{hr}$, washed twice with PBS containing $0.05 \%$ Tween-20, and probed with $4 \times 10^{6}$ counts per minute (cpm) ${ }^{125}$ I-AGE-BSA for $1 \mathrm{hr}$ in the presence or absence of cold AGE-BSA (100-fold excess). The blots were washed extensively with PBS/Tween-20, air dried, and exposed to XAR film (Kodak, Rochester, NY, USA) at $-80^{\circ} \mathrm{C}$. Bound radioactivity was quantified by a phosphoimager (Packard, Meriden, CT, USA) and expressed as the percent of cpm bound by a given protein species/total cpm associated with the respective lane. This procedure was repeated at least three times using cell extracts from different cell preparations.
For Western blotting, samples were electrophoresed and transferred to nitrocellulose membranes, as described $(12,18)$. The membranes were subsequently blocked using $2 \%$ dry milk in PBS/Tween-20 for $1 \mathrm{hr}$ and incubated with primary antibody for $\mathrm{l} \mathrm{hr}$. The appropriate peroxidaseconjugated secondary antibody was then added at a final dilution of 1:2000 for $1 \mathrm{hr}$. The immunoreactive species were detected using the electrochemilluminescence method (ECL; Amersham, Piscataway, NJ, USA). Equal sample loading onto membranes was assessed by using Amido black staining.

Total RNA was extracted from cells using RNAzol solution (TET-TEST Inc., Friendswood, TX, USA) and RT-PCR was performed, using a Boehringer Mannheim kit $(36,37)$. The following primers were used: Human AGE-Rl: sense: GCT, CTT, CCA, CTC, CTT, ACT, CCT; antisense CCA, GAC, AGG, CAA, CTA, TGA, AC: AGE-R2 sense: TGG, TGT, GGT, GGC, TAT, TGA, CCT, TTG, C; antisense: CGC, AGT, AGT, CGT, CGT, TCA, CCT, GAT, C]; AGE-R3: sense: CAC, CTG, CAC, CTG, GAG, TCT, AC; antisense: GCA, CTG, GTG, AGG, TCT, ATG, TC. Total PBMN cell RNA was reversetranscribed to cDNA. Mutants of AGE-receptors were constructed by a deletion made in the original PCR products, as described $(36,37)$. Equal amounts of mutant were added to each PCR tube containing the unknown cDNA, for competition. PCR products were separated on $3 \%$ agarose gel. cDNA and mutant bands were scanned by a computer-assisted densitometry. The ratio of $\mathrm{cDNA} /$ mutant was used to express the amount of AGE-receptor cDNA.

At least three different mutant concentrations were used for each cDNA. $\beta$-actin was used as a control in each sample. A competitive PCR for $\beta$-actin was also performed for each sample and the data were expressed as the ratio of AGE-R cDNA/mutant to $\beta$-actin cDNA/mutant. All experiments were performed in triplicate.

\section{Serum and Tissue AGE Determination}

AGE levels were determined in aliquots of tissue extracts or serum samples by a competitive AGEELISA, using well-characterized polyclonal rabbit antisera raised against AGE-RNAse or by monoclonal anti-AGE-KLH (43). Although not all epitopes recognized by the polyclonal antibody have been identified, this and the monoclonal antibody recognize ${ }^{\varepsilon} \mathrm{N}$ carboxymethyllysine (CML)-like epitopes, and both exhibit similar cross-reactivity for in vivo formed AGEs (44). Pooled normal human serum was used as an internal control, as described (44). The data were expressed as AGE U/ml serum or U/mg tissue.

\section{Statistics}

Differences in cellular AGE-R mRNA or protein levels among the respective groups were analyzed using ANOVA and Student's $t$ test (two-tailed $p$ values $<.05$ were considered significant). In some 
instances, where SEM values indicated large coefficient of variation, a nonparametric, distribution-free test (Kruskel-Wallis test, of Dunn's procedure) was also performed. The relationships among various parameters were examined by regression analysis. All data were expressed as the mean \pm SD of at least three identical experiments, unless otherwise indicated.

\section{Results}

AGE-R Protein Expression and Activity in NOD-Mouse Macrophages

Consistent with previous findings $(36,37)$, NOD mice (3-4 months old) exhibited high levels of AGE in serum $(48 \pm 12 \mathrm{U} / \mathrm{ml}, p<.005)$ and in kidneys ( $24 \pm 6 \mathrm{U} / \mathrm{mg}$ tissue, $p<.001$ ), as compared to genetically related, nondiabetic RD-resistant ILI mice (serum AGE, $8 \pm 3 \mathrm{U} / \mathrm{ml}$; kidney AGE, $10 \pm 4 \mathrm{U} /$ $\mathrm{mg})$. Because macrophages/monocytes are involved in the turnover of AGE, we tested peritoneal macrophages from these mice for membrane AGE$\mathrm{R} 1$, -R2, and -R3 protein expression and ligand binding. To test the possible influence of insulin or glucose changes, experiments were performed on cells from both pre-diabetic and diabetic NOD mice (Fig. 1). Consistent with earlier data on NOD mesangial cells $(37,38)$ prior to diabetes, NOD macrophage cell membranes exhibited reduced levels of AGE-RI immunoreactivity compared to ILI, without notable differences in AGE-R2 or -R3 (Fig. 1A). ${ }^{125} \mathrm{I}$-A GE-specific binding (at $0.5 \mathrm{uM}^{125} \mathrm{I}-$ AGE-BSA) by cultured NOD macrophages was sig- nificantly lower (2.5-fold, $p<.025$ for $\mathrm{n}-\mathrm{db}$ and $\mathrm{db}$ NOD) than in ILI cells, and ${ }^{125}$ I-AGE-degradation (at $0.75 \mathrm{uM}{ }^{125} \mathrm{I}$-AGE-BSA) was also significantly below that of ILI cells $(p<.01$ and $p<.005$, respectively) (Fig. 1B and C).

\section{AGE-Receptor mRNA and Protein Levels in PBMN of T1D Patients With or Without Diabetic Complications}

Reduced NOD macrophage AGE-R activity, in connection to high serum AGE (sAGE) levels, was consistent with suppressed renal AGE-R function in this mouse model, compared to the related $\mathrm{DN}$ resistant strain ILI $(36,37)$. These observations prompted us to study AGE-receptor gene expression in two groups of TID patients matched for age and disease duration, but differing in the presence of overt DN. Patient epidemiologic data are summarized in Table 1. Elevated HbAlc was present in both DM groups, while significant albuminuria (as assessed by UAER) and dyslipidemia (fasting hypertriglyceridemia) were present only in the DM/ DC patients; in most instances, the latter presented with a history of clinically significant cardiovascular and peripheral vascular disease, retinopathy, or neuropathy. As shown in Table 1, sAGE were significantly elevated in both DM groups, although more so in DM/DC compared to NL (DM/nDC, $p<$ .05; DM/DC, $p<.005)$, in a manner that correlated inversely with creatinine clearance $\left(\mathrm{C}_{\mathrm{cr}}\right)(r=-.67$, $p<.05)$. Consistent with the elevated sAGE levels, urinary AGE excreation and AGE clearance $\left(\mathrm{C}_{\mathrm{AGE}}\right)$
A

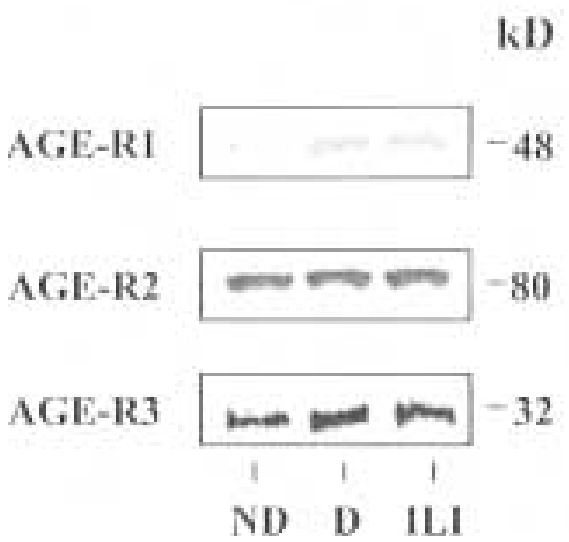

\section{$k$ D)}

B

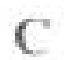

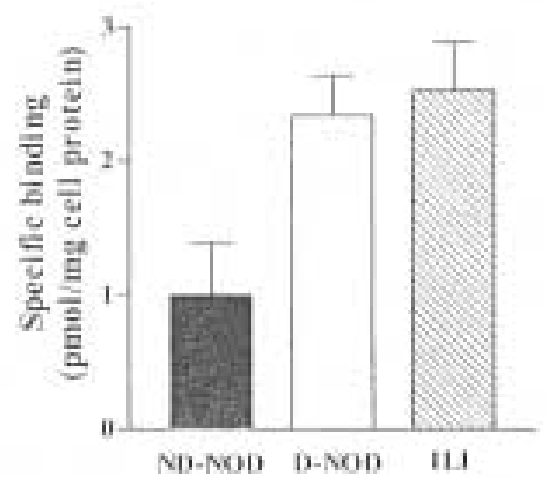

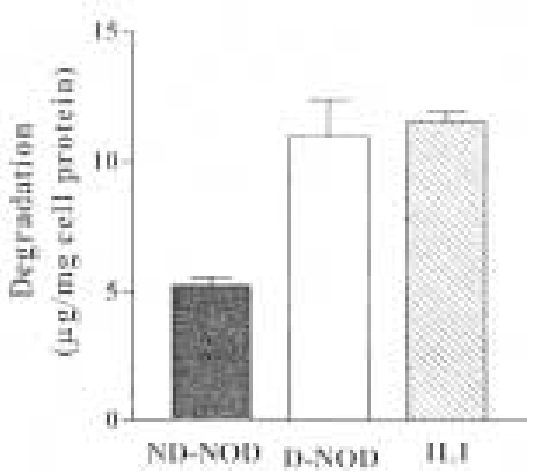

Fig. 1. AGE-R1 protein expression, ligand binding and degradation are reduced in NOD mouse peritoneal macrophages. (A) Peritoneal macrophage membrane AGE-R1, -R2, and -R3 were determined by Western blot analysis on membrane extracts from 3- to 4-month-old ND-NOD, D-NOD, and ILI (control) mice ( $n=10$ per group). After electrophoresis on $12 \%$ gels, samples were transferred and immunoblotted with the respective anti-lgG, and visualized by ECL (anti-R1, 50 $\mu \mathrm{g} / \mathrm{ml} ;$ anti-R2, 50 $\mu \mathrm{g} / \mathrm{ml}$; anti-R3, $10 \mathrm{ug} / \mathrm{ml}$ ). Molecular weights are indicated on the right side of the panel. Protein concentration used was $20 \mu \mathrm{g}$ per lane. Data are representative of five identical experiments. (B) Binding of AGE-BSA to NOD mouse peritoneal macrophages (1 $\times 10^{6}$ per well, at $4^{\circ} \mathrm{C}$ for $\left.2 \mathrm{hrs}\right)$ using ${ }^{125} \mathrm{I}$-AGE-BSA $(0.1-0.5 \mu \mathrm{m})$ as a probe in the presence or absence of 50-fold excess unlabeled AGE-BSA. (C) Degradation of AGE-BSA by NOD mouse macrophages was performed at $37^{\circ} \mathrm{C}$ for 4 hrs and determined by measurement of trichloroacetic acid-soluble radioactivity in the medium. Data represent triplicate values and are expressed as the mean \pm SEM. For panel B: $p$ values: ND-NOD versus ILI, <.005; D-NOD versus ILI, NS. For panel C: $p$ values: ND-NOD versus ILI: <.002, D-NOD versus ILI: NS. 
was enhanced in DM/n-DC patients $(p<.05$ versus $\mathrm{NL}$ ), but significantly reduced in DM/DC patients $(p<.025$ versus NL), which was consistent with the presence of overt nephropathy (Table 1) $(33,34)$.

Peripheral blood mononuclear (PBMN) cells from diabetic patients with no evidence of overt nephropathy or other complications (DM/n-DC) exhibited enhanced expression of AGE-RI mRNA (nearly 2-fold) compared to NL control PBMN ( $p<$ .05) (Fig. 2A). A similar observation was made for AGE-R3 ( 2.5-fold higher in DM/n-DC than in normal PBMN), and, less consistently, for AGE-R2 mRNA levels (Fig. 2B and C). These changes were proportional to the increases in SAGE levels (Table 1). In contrast, cells from patients with overt DN, despite even higher sAGE levels (Table 1), showed no stimulation of AGE-R I mRNA, which remained near the NL level, or at $\sim 50 \%$ of the $-\mathrm{R} 1$ of DM/n-DC PBMN $(p<.01)$ (Fig. 2A). PBMN from this group, however, exhibited a distinct increase in AGE-R2 mRNA (1.8-fold, $p<.025)$, and in-R3 mRNA $(\sim 2.8$ fold, $p<.005)$ above NL (Fig. 2B,C), in keeping with elevated sAGE levels (Table 1). Due to the small population sample, a Kruskal-Wallis test (Dunn procedure) was also performed. The dif-
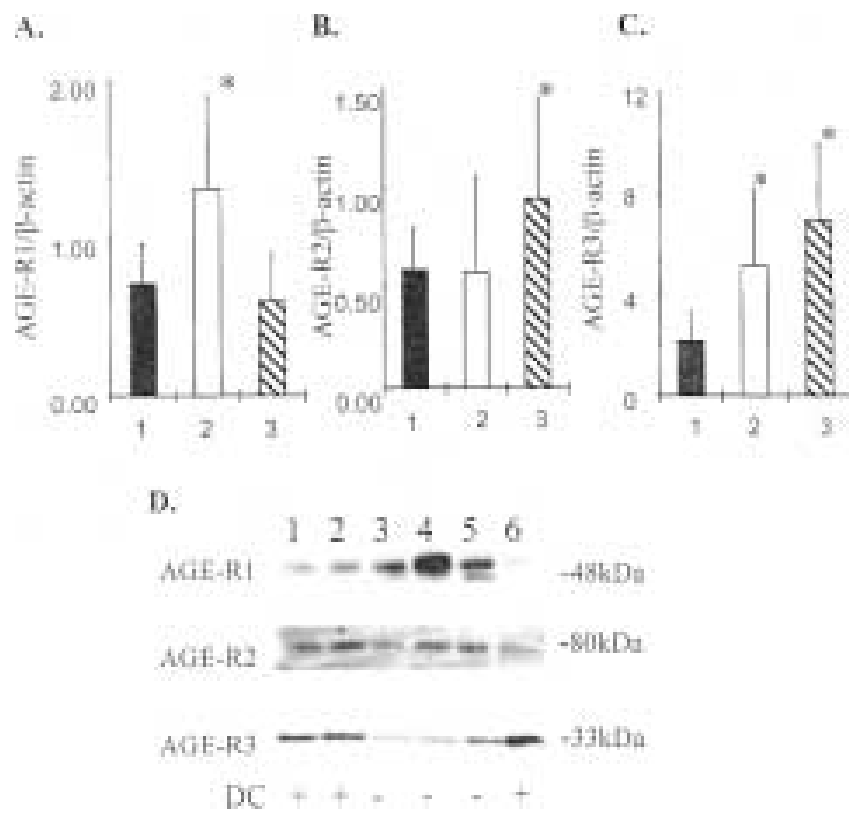

Fig. 2. AGE-receptor mRNA levels in PBMN from normal subjects (NL, bar 1), T1D patients without DC (n-DC, bar 2) and with diabetic complications (DC, bar 3). (A) AGE-RI. (B) AGE-R2 (C) AGE-R3. AGE-receptor/ $\beta$-actin mRNA ratios were assessed in freshly isolated PBMN, by competitive RTPCR, as described (35). mRNA levels were expressed as the ratio of AGE-R cDNA/mutant to $\beta$-actin cDNA/mutant. * $p<.05$, compared to nondiabetic individuals. (D) Western blot analysis of PBMN membrane samples from a randomly selected group of TID patients was performed as described in Fig. 1, using the respective anti-R1, - R2, and - R3 anti-IgG, at same concentrations. Blots were visualized by ECL. Presence of DC is indicated by + or - . Molecular weights are indicated on the right side of the panel. ferences in AGE-RI mRNA expression in DM/DC versus $\mathrm{DM} / \mathrm{n}-\mathrm{DC}$ and NL were highly significant $(p=.0002$ and $p=.003$, respectively), as were the differences in AGE-R3 mRNA in the same groups ( $p=.010$ and $p=.05$, respectively). The variation of AGE-R2 mRNA was not found to be statistically significant based on this method. The relative level of protein expression of AGE-R1, -R2, and -R3 components was examined individually in each of the respective groups of patients (a subgroup of six randomly selected patient samples is shown in Fig. 2D) via Western analysis. Consistent with the mRNA data, PBMN membrane fractions from the DM/DC group displayed low AGE-R 1 protein immunoreactivity (IR) (lanes 1, 2, and 6), which was substantially below that observed in PBMN from patients free of DC (lanes 3, 4, and 5) and directionally opposite to the mean sAGE level for the respective group (Table 1). By comparison, cells from the same subjects expressed enhanced AGE-R3 levels, compared to cells from DM/n-DC. A less distinct pattern of IR was observed with AGE-R2 protein from each patient by this method.

However, in these samples of freshly isolated PBMN, a significant positive correlation was observed between sAGE levels and PBMN AGE-R2 mRNA $(r=.65, p<.05)$ (Fig. 3B), but not with - R3 mRNA levels $(r=0.35, p>0.05)$ (Fig. 3C) and -R 1 mRNA ( $r=0.1, p>0.05)$ (Fig. 3A). Also, a significant correlation was observed between fresh PBMN AGE-R2 mRNA and creatinine clearance rate in DM/DC group $(r=-.63, p<.05)$ (data not shown). No correlation was found between AGE-R1, -R2, or R3 mRNA and age, sex, duration of diabetes, HbAlc, or lipid levels in these patients, although a distinct rise in serum triglycerides was noted in patients with DN (DM/DC versus DM/n-DC, $p<.05)$ (Table 1$)$.

\section{AGE-Receptor mRNA Levels in EBV-Transfected Lymphoblast Cells}

To assess the influence of the metabolic milieu on the AGE-R cellular phenotype, AGE-R mRNA levels were examined in $18 \mathrm{EBV}$-transfected lymphoblast cell lines obtained from six nondiabetic individuals, six patients with TID but no evidence of DC (DM/n-DN), and six TID patients with end-stage renal disease (ESRD) (DM/DC). Consistent with circulating PBMN cells, transformed cells from DM/DC patients exhibited suppressed AGE-R I mRNA levels compared to lymphoblasts from DM/n-DN patients $(p<.025)$ and even to those from nondiabetic subjects $(p<.01)$ (Fig. 4A). However, unlike the freshly isolated PBMN cells, transformed cells from either of the diabetic groups under culture conditions exhibited no differences in AGE-R2 or- R3 mRNA expression (Fig. 4B and C).

\section{Discussion}

The discovery of a receptor-mediated mechanism for the uptake and removal of tissue damaging 
A.

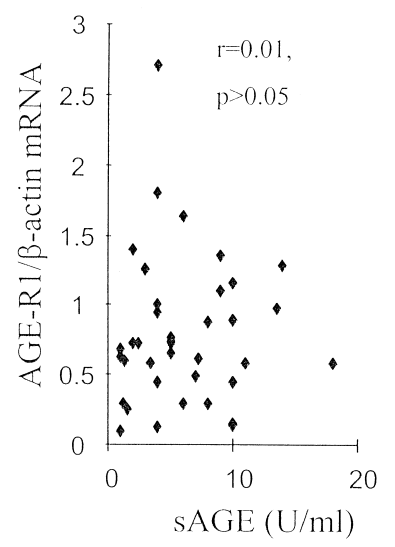

B.

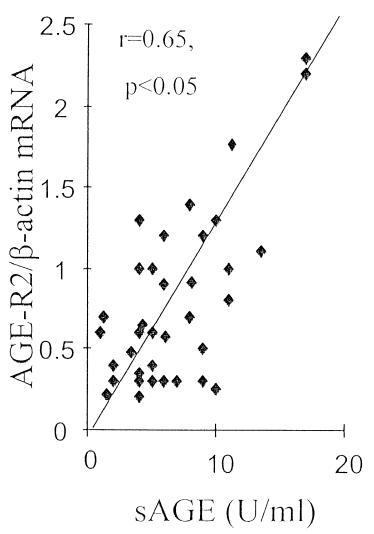

C.

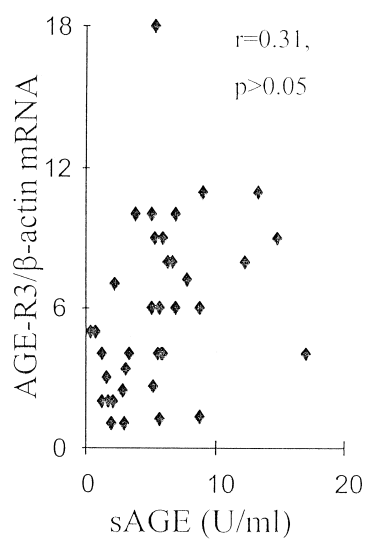

Fig. 3. Correlation between AGE-receptor 1, -R2, -R3 mRNA levels and serum AGE levels in T1D patients with, and without DC. AGE-R1 (A), AGE-R2 (B), and AGE-R3 (C) mRNA levels were measured by RT-PCR (35), and expressed as the ratio of AGE-R cDNA/mutant to $\beta$-actin cDNA/mutant. Serum AGE levels were determined by ELISA (42) and expressed as AGE U/mL serum. $R$ and $p$ values after regression analysis are shown as insets.

glycoxidants, or AGEs, has identified a housekeeping system that is believed to serve at least two important tightly balanced functions: removal of AGE-modified elements, and new growth promotion or tissue repair (29). The system is thought to include autoregulatory switches, allowing it to control AGE levels in tissues $(25,28)$. The means by which this balance is maintained in vivo during times of excessive AGE accumulation, as in diabetes, renal disease, or aging, is largely unknown; however, it is likely to be influenced by as yet undefined metabolic or genetic factors. In this context, studies have indicated that excess AGEs, as in chronic diabetes, aging, or renal failure $(23,25,33)$, may tip this balance toward injurious pro-oxidant and pro-inflammatory events (29).
This may be promoted by AGE-receptor-dependent signaling molecules (e.g., RAGE [19], AGE-R2 $[13,20]$, or AGE-R3 [16]), or by receptor-independent mechanisms, each of which could initiate chronic tissue injury. Alternatively absence or malfunction of the AGE-removing properties of the AGE receptor could lead to large AGE tissue deposits. Delayed AGE processing and disposal could stimulate the inflammatory events mentioned above, tipping the balance in the direction of organ function.

The first evidence in support of this hypothesis was obtained from recent findings of disproportionately high kidney tissue AGE and reduced mesangial cell AGE-receptor total binding capacity in NOD mice, a diabetic animal model that is prone to

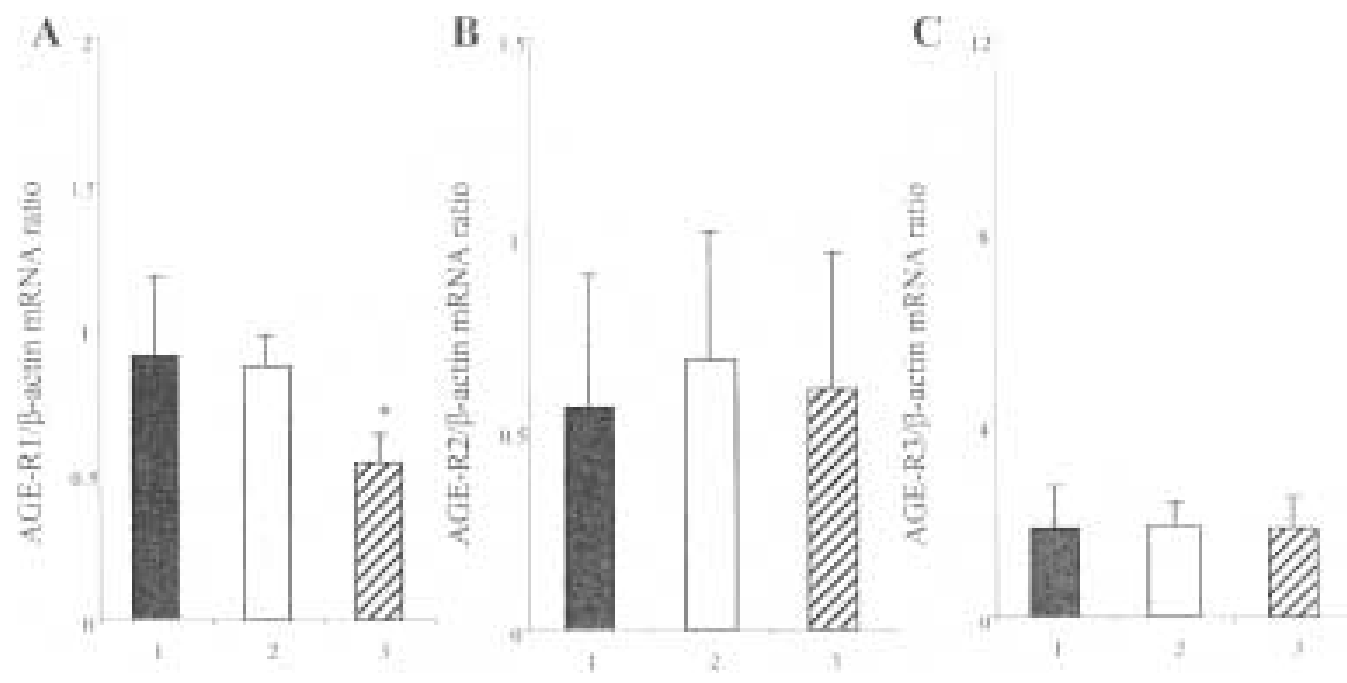

Fig. 4. AGE-R1, -R2, and -R3 mRNA levels in EBV-transfected lymphoblast cell lines from T1D patients with and without DC. Transformed lymphoblasts $\left(1 \times 10^{7}\right.$ per patient) obtained as described in methods section were suspended in RPMI (10\% FBS) prior to being subjected to RNA isolation procedure, as described in Fig. 1 (35). AGE-R1 (A), -R2 (B), -R3(C), and $\beta$-actin mRNA levels were measured by competitive RT-PCR (35). Data are expressed as the ratio of each AGE-R cDNA/mutant to $\beta$-actin cDNA/mutant. ${ }^{*} p<.05$ as compared to nondiabetic control individuals. 
diabetes-promoted kidney damage $(36,37)$. The findings were associated with low expression and activity of only a single receptor component, AGE-Rl, and none of the other candidate receptor genes, -R2, -R3, RAGE or ScR-II, which suggested the importance of $\mathrm{R} I$ for cell-mediated AGE processing and degradation in the kidney. However, the role of monocytes/ macrophages as the principal AGE-removing cells was not assessed in that study; thus, the findings could not be generalized to a failure of the AGE removal system. The data presented herein indicate a similar reduction in AGE-R 1 protein expression in NOD mouse macrophages. In addition, they demonstrate reduced AGE uptake and degradation by these cells, which can be attributed at least in part to insufficiently expressed and/or dysfunctional AGE receptor- 1 . These findings, together with the mesangial cell culture data (37) suggest a systemic impairment in AGE-R-dependent AGE turnover in this model.

In support of, and as an extension beyond the NOD mouse model, evidence from fresh human diabetic PBMN and from immortalized lymphoblasts from TID patients removed from the diabetic environment suggests that an intrinsic imbalance in the AGE-removing capacity by this receptor exists in certain patients who display accelerated progression to major organ damage (e.g., nephropathy and vasculopathy) $(1,5,40,41)$. The phenotype of low AGE$\mathrm{Rl}$ gene expression retained in lymphoblast cultures, taken together with the NOD mouse data, indicates the possible involvement of genetic modulators in ways that could contribute to organ damage. The population of patients with significant diabetic nephropathy studied herein, although small, was similar in age and diabetic duration to the group that remained free of complications. Thus, each subgroup presented a clearly different response to the same "diabetes-related" injury promoting factors (e.g., plasma glucose, lipidemia, AGE levels, etc). Of note, in the complications-free patients, the levels of expression of AGE-R 1 gene and protein product correlated with elevated levels of sAGEthe latter presumably reflecting an equilibrium with increased tissue AGE. This suggests that clinically relevant AGE elevations can up-regulate normal macrophage/monocyte turnover of AGE so that toxic derivatives can be excreted in the urine. This was reflected in the significantly higher rate of urinary AGE clearance in n-DC patients, compared to normal subjects; higher turnover rate and timely disposal of systemic AGEs might in turn have helped preserve physiologic renal function in these patients. The contrary may be presumed to occur in the patients with DC: AGE-R I mRNA levels in this group, although detectable, exhibited a failure to respond to elevated sAGE as seen in the DC-free group, thus possibly delaying the process of AGE degradation and urinary excretion. Indeed, the low level of expression of this molecule was not affected by, nor was it linked to, elevated sAGE, HbAlc, or plasma triglyceride levels. This $\mathrm{R} 1$ response was also dissociated from the responses of other receptor component, such as -R2 which correlated well with SAGE and creatinine clearance.

Patients with DN are reported to have elevated sAGE due to a decrease in renal clearance of AGE catabolic products $(33,34)$. In this study, because most patients in the DC group presented with overt nephropathy, impaired renal AGE clearance could have been the main determinant of high sAGE, which in turn could have triggered cellular AGE-R2 or -R3 expression. Elevated AGE levels are also a source for cellular ROS generation, known to induce and be induced by AGE-interactive molecules, such as RAGE $(10,19)$. Expression of RAGE as well as ScR-II $(21,22)$ is reported to be enhanced in human diabetic tissues, as well as in NOD mouse kidneys (37), and could thus be involved in inflammatory processes preceding DN. Although this is plausible, the overexpression of these molecules was not sufficient to normalize the abnormally high AGE in the NOD mouse kidney; also this does not support their presumed role in the endocytosis/degradation of AGE. Several polymorphisms have been identified on the human RAGE gene; however, no relationship to diabetic complications is found thus far (24 and F. Cambien, personal communication). The inverse relationship of AGE-Rl gene expression to serum AGE, confined to the DC-prone patients could provide a tentative explanation, raising the possibility of an intrinsically defective cellular AGE disposal mechanism. Indeed, such an intrinsic defect could underlie or precede events leading to impaired renal function and a cyclic re-enforcement of the response to injury. This is supported by the cultured lymphoblast data, in which a markedly suppressed AGE-R1, but not -R2 or -R3 mRNA, was restricted to those patients with severe DN. These latter findings support the possibility of an intrinsic AGE regulatory genetic defect that, in certain subjects, may result in impaired AGE receptor efficiency and high sAGE levels, enhanced by hyperglycemia or uremia. No differences were found in AGE-R2 and -R3 mRNA transcripts in cultured lymphoblasts between the diabetic groups. These data lend further support to the possibility that the differences in the expression of $-\mathrm{R} 2$ and $-\mathrm{R} 3$ receptors found in fresh PBMN were due to exposure of PBMN to the diabetic milieu and not genetic in nature.

An inverse balance between $\mathrm{R} 1$ and -R2/-R3 immunoreactivity was observed in PBMN from the same patient, despite individual variation: normal or elevated $-\mathrm{R} 1$ protein expression corresponded to low $-\mathrm{R} 2$ and even lower -R3 protein levels in several patients, none of whom had signs of organ damage. The opposite trend was observed in patients with DC: suppressed AGE-R I was linked to a reciprocal increase in -R2 and -R3. This could be attributed in part to one common in vivo denominator of these interactions, the sAGE level, as this was absent in cultured 
cells. Indeed the significant inverse relationship of -R2 mRNA level and SAGE found in these studies is both intriguing and novel. While further studies will be needed to elucidate these relationships, it is certainly interesting to speculate on the nature and significance of these findings.

Regarding the possible effect due to the diabetic environment of these patient groups, namely hyperglycemia, hyperlipidemia, high AGE, low or variable insulin level, or uremic factors, the data from lymphoblasts studied in the absence of such metabolites confirmed a unilateral suppression of AGE-RI in cells from patients with severe diabetic kidney disease. This was in support of a defective gene expression for AGE-R1, but not for the other two receptor components, independent of the environment. It also provided further evidence that AGE-RI is important for normal tissue AGE homeostasis. No direct receptor affinity studies were possible in the patients of this study; however, based on the evidence obtained from the NOD mice (37, and herein), where susceptibility to DN is associated with low AGE-R I gene expression level, and loss in AGE uptake, and degradative capacity, it is reasonable to expect that underexpression of AGE-RI mRNA and protein in human cells may coincide with impaired monocyte/macrophage-mediated AGE turnover, occurring with higher frequency in persons predisposed to DC. The alternative possibility exists that excess AGE due to the presence of renal insufficiency exerts differential control on AGE-R components. Although no data are available from these patients prior to the rise of serum AGE, the high serum AGE levels in pre-diabetic NOD mice is suggestive of an underlying intrinsic defect, independent of diabetes (37). In this context, several polymorphisms have been identified in the human AGE-R1/OST-48 gene, one of which suggests a possible link to diabetic retinopathy, but none was strongly associated with diabetic nephropathy (F. Cambien, personal communication). Further studies are in progress to establish the significance of such polymorphisms, to test whether a primary or secondary genetic link exists between AGE$\mathrm{R} 1$ and the pathology of DC.

\section{Acknowledgments}

This work was funded in part by the National Institutes of Health (Grant \#AG09453). We wish to thank Dr. Andrzej Krolewski for generously providing us with TID EBV-transformed lymphoblasts and relevant epidemiologic data as well as with helpful advice. The editorial assistance of Ina Katz is greatly appreciated.

\section{References}

1. Andersen AR, Christiansen JS, Andersen JK, Kreiner S, Deckert T. (1983) Diabetic nephropathy in type 1 (insulindependent) diabetics: an epidemiological study. Diabetologia 25: 496-501.
2. Krolewski AS, Canessa M, Warram JH, Laffel LM, Christlieb AR, Knowler WC, Rand LI. (1988) Predisposition to hypertension and susceptability to renal disease in insulin-dependent diabetes mellitus. N. Engl. J. Med. 318: 140-145.

3. Moczulski DK, Rogus JJ, Antonellis A, Warram JH, Krolewski AS. (1998) Major susceptibility locus for nephropathy in type 1 diabetes on chromosome 3q: results of novel discordant sib-pair analysis. Diabetes 47: 1164-1170.

4. Seaquist ER, Goetz FC, Rich S, Barbosa J. (1989) Familial clustering of diabetic kidney disease: evidence for genetic susceptibility to diabetic nephropathy. N. Engl. J. Med. 320: 1161-1165.

5. Ng LL, Davies JE, Siczhowski MM, Sweeney FP, Quinn PA, Krolewski B, Krolewski AS. (1994) Abnormal Na+/H+ antiporter phenotyope and turnover of immortalized lymphoblasts from type 1 diabetic patients with nephropathy. J. Clin. Invest. 93: 2750-2757.

6. Parving H-H. (1998). Renoprotection in diabetes: genetic and non-genetic risk factors and treatment. Diabetologia 41: 745- 759.

7. Doria A, Warram JH, Krolewski A. (1994) Evidence for the role of the angiotensin I-converting enzyme gene. Diabetes 43: 690-695.

8. Ruderman NB, Williamson JR, Brownlee M. (1992) Glucose and diabetic vascular disease. FASEB J. 6: 2905-2914.

9. Brownlee M. (1995) Advanced protein glycosylation in diabetes and aging. Annu. Rev. Med. 46: 223-234.

10. Schmidt AM, Yan SD, Wautier J-L, Stern D. (1999) Activation of receptor for advanced glycation end products, a mechanism for chronic vascular dysfunction in diabetic vasculopathy and atherosclerosis. Circ. Res. 84: 489-497.

11. Yang Z, Makita Z, Horii Y, Brunelle S, Cerami A, Sephajpal P, Suthanthiran M, Vlassara H. (1991) Two novel rat liver membrane proteins that bind advanced glycosylation enproducts: relationship to macrophage receptor for glucose-modified proteins. J. Exp. Med. 174: 515-524.

12. Li Y-M, Mitsuhashi T, Wojciehowicz D, et al. (1996) Molecular identity and cellular distribution of advanced glycation endproduct receptors: relationship of p60 to OST-48 and p90 to $80 \mathrm{~K}-\mathrm{H}$ membrane proteins. Proc. Natl. Acad. Sci. USA 93: 11047-11052.

13. Goh KC, Lim YP, Ong SH, Siak CB, Cao X, Tan YH, Guy GR. (1996) Identification of p90, a prominent tyrosinephosphorylated protein in fibroblast growth factor stimulated cells, as 80K-H. J. Biol. Chem. 271: 5832-5838.

14. Sakai K, Hirai M, Minoshima S, Kidoh J, Fukuyama R, Shimizu N. (1989) Isolation of cDNAs encoding a substate for protein kinase C: nucleotide sequence and chromosomal mapping of the gene for a human $80 \mathrm{~K}-\mathrm{H}$ protein. Genomics 5: 309-315.

15. Stitt A, He C, Vlassara H. (1999) Characterization of the advanced glycation end-product receptor complex in human vascular endothelial cells. Biochem. Biophys. Res. Comm. 256: 549-556.

16. Vlassara H, Li YM, Imani F, Wojciechowicz D, Yang Z, Liu F, Cerami A. (1995) Identification of galectin-3 as a high affinity binding protein for advanced glycation enproducts (AGE): a new member of the AGE-receptor complex. Mol. Med. 1: $634-646$.

17. Kadrofske M, Openo KP, Wang JL. (1998) The human LGALS3 (galectin-3) gene: determination of the gene structure and functional characterization of the promoter. Arch. Biochem. Biophys. 349: 7-20.

18. Stitt AW, Li YM, Gardiner TA, Bucala R, Archer DB, Vlassara H. (1997) Advanced glycation end products (AGEs) co-localize with AGE receptors in the retinal vasculature of diabetic and of AGE-infused rats. Am. J. Pathol. 150: 523-539.

19. Neeper M, Schmidt AM, Brett J, et al. (1992) Cloning and expression of a cell surface receptor for advanced glycosylation end products of proteins. J. Biol. Chem. 267: 14998-15004.

20. Landers HM, Tauras JM, Ogiste JS. (1989) Isolation of CDNAs encoding a substate for protein kinase C: nucleotide sesquence and chromosomal mapping of the gene for a human $80 \mathrm{~K}-\mathrm{H}$ protein. J. Biol. Chem. 272: 17810-17814. 
21. Khoury J, Thomas C, Loike J, Hickman S, Cao L, Silverstein S. (1994) Macrophages adhere to glucose-modified basement membrane via their scavenger receptors. J. Biol. Chem. 269: 10197-10200.

22. Suzuki H, Kurihara Y, Takeya M, et al. (1997) A role for macrophage scavenger receptors in artherosclerosis and susceptibility to infection. Nature 386: 292-296.

23. Yamagata T, Tsuru T, Momoi M, et al. (1997) Genome Organization of Human $48-\mathrm{kDa}$ Oligosaccharryltranferase (DDOST). Genomics 45: 535-540.

24. Hudson BI, Stickland MH, Grant PJ. (1998) Identification of polymorphisms in the receptor for advanced glycation end products (RAGE) Gene, Diabetes 47: 1155-1157.

25. Vlassara H, Brownlee $M$, Cerami A. (1988). Specific macrophage receptor activity for advanced glycosylation end products inversely correlates with insulin levels in vivo. Diabetes 37: 456-461.

26. Stitt AW, He C, Friedman S, et al. (1997) Elevated AGEmodified ApoB in sera of euglycemic, normolipidemic patients with atherosclerosis: relationship to tissue AGEs. Mol. Med. 3: 617-627.

27. Sano H, Higashi T, Matsumoto $K$, et al. (1998) Insulin enhances macrophage scavenger receptor-mediated endocytic uptake of advanced glycation end products. J. Biol. Chem. 273: 8630-8637.

28. Vlassara H, Moldawer L, Chan C. (1989) Macrophage/ monocyte receptor for nonenzymatically glycosylated protein is upregulated by cachectin/tumor necrosis factor. J. Clin. Invest. 84: 1813-1820.

29. Vlassara H, Bucala R, Striker L. (1994) Pathogenic effects of advanced glycosylation: biochemical, biologic, and clinical implications for diabetes and aging. Lab. Invest. 70: 138-151.

30. Shinohara $\mathrm{M}$, Thornalley $\mathrm{PJ}$, Giardino $\mathrm{I}$, Beisswenger $\mathrm{P}$, Thrope SR, Onorato J, Brownlee M. (1998) Overexpression of glyoxalase-I in bovine endothelial cells inhibits intracellular advanced glycation endproduct formation and prevents hyperglycemia-induced increases in macromolecular endocytosis. J. Clin. Invest. 101: 1142-1147.

31. Cohen MP, Ziyadeh FN, Lautenslager GT, Cohen JA, Shearman CW. (1999) Glycated albumin stimulation of PKC-beta activity is linked to increased collagen IV in mesangial cells. Am. J. Physiol. 276: F684-690.

32. Vlassara H. (1989) Advanced non-enymatic tissue glycosylation: mechanism implicated in the complications associated with aging. In: Clegg M, O'Brien S (eds) Molecular Biology of Aging. Alan R. Liss, Inc., New York, pp. 171-185.

33. Makita Z, Radoff S, Rayfield EJ, et al. (1991) Advanced
Glycation Enproducts in patients with diabetic nephropathy. N. Engl. J. Med. 325: 836-842.

34. Makita Z, Bucala R, et al. (1994) Reactive glycosylation endproducts in diabetic uraemia and treatment of renal failure. Lancet 343: 1519-1522.

35. Doi T, Hattori M, Agodoa LY, Sato T, Yoshida H, Striker LJ, Striker GE. (1990) Glomerular lesions in nonobese diabetic mouse: before and after the onset of hyperglycemia. Lab Invest. 63: 204-212.

36. Yang CW, Hattori M, Vlassara H, et al. (1995) Overexpression of transforming growth factor-beta 1 mRNA is associated with up-regulation of glomerular tenascin and laminin gene expression in nonobese diabetic mice. J. Am. Soc. Nephrol. 5: $1610-1617$.

37. He C, Zheng F, Stitt A, Striker L, Masakazu H, Vlassara H. (2000) Differential expression of renal AGE-receptor genes in NOD mice; possible role in NOD diabetic renal disease. Kidney Int. (in press).

38. He C, Stitt A, Striker L, Hatori M, Vlassara H. (1996) Low expression of AGE-receptor-1 in NOD mouse mesangial cells: possible link to diabetic nephropathy. J. Am. Soc. Nephrol. 7: 1871 (Abstr).

39. He C, Koschinsky T, Sabol J, Buenting C, Liu C, Vlassara H. (1997) Mononuclear (MN) cell AGE receptor-1 (AGE-R1) mRNA expression and its relationship to diabetic complications. Diabetes Supplement. 46: 8A (Abstr).

40. Leong LN, Davies JE, Siczowski M, Sweeney FP, Quinn PA, Krolewski B, Krolewski AS. (1994) Abnormal Na+/H+ antiporter phenotype and turnover of immortalized lymphoblasts from type 1 diabetes patients with nephropathy. J. Clin. Invest. 93: 2750-2757.

41. Rogus JJ, Krolewski AS. (1996) Using discordant sib pairs to map loci for qualitative traits with high sibling recurrence risk. Am. J. Hum. Genet. 59: 1376-1381.

42. Beisswenger PJ, Makita Z, Curphey TJ, et al. (1995) Formation of immunochemical advanced glycosylation end products precedes and correlates with early manifestations of renal and retinal disease in diabetes. Diabetes 44: 824-829.

43. Makita Z, Vlassara H, Cerami A, Bucala B. (1992) Immunochemical detection of advanced glycosylation end products in vivo. J. Biol. Chem. 267: 5133-5138.

44. Zyzak DV, Richardson JM, Thorpe SR, Baynes JW. (1995) Formation of reactive intermediates from Amadori compounds under physiological conditions. Arch. Biochem. Biophys, 316: $547-554$.

45. Quinn M, Angelico MC, Warram JH, Krolewski AS. (1996) Familial factors determine the development of diabetic nephropathy in patients with IDDM. Diabetologia 39: 940- 945. 